\title{
Effects of Ca Addition on Solidification Structure of Cu-Sn-Zn Bronze Castings
}

\author{
Kazuhiro Matsugi ${ }^{1}$, Takayuki Hino ${ }^{1, *}$, Gen Sasaki $^{1}$, Osamu Yanagisawa ${ }^{1}$ and Minoru Kidani ${ }^{2}$ \\ ${ }^{1}$ Department of Mechanical Materials Engineering, Hiroshima University, Higashi-Hiroshima 739-8527, Japan \\ ${ }^{2}$ Shinko Ind. Ltd., Hiroshima 732-0802, Japan
}

\begin{abstract}
The substitution of $\mathrm{Ca}$ for a part or all of $\mathrm{Pb}$ in $\mathrm{Cu}-\mathrm{Sn}-\mathrm{Zn}$ alloys of 88-8-4 type was carried out in order to decrease solidification defects. The relation between cooling rate and segregation of alloying elements or solidification defects was investigated using steps shaped ingots. Finer dendrite structure was obtained due to decrease in the diffusion coefficient and mass transfer of $\mathrm{Sn}$ or $\mathrm{Zn}$ in the $\mathrm{Cu}$-liquid for $\mathrm{Ca}$ addition alloys. The concentration of $\mathrm{Ca}$ and the amount of the micro shrinkage cavity in each step was almost constant in Ca added alloys. The same segregation course in the solidification path showed in both 88-8-4-Pb (CAC402) and 88-8-4-Pb-Ca alloys. In Ca added alloys, the enrichment of Sn in the residual liquid and decrease in final solidification temperature were suppressed by expenditure of Sn due to formation of the compounds consisting of $\mathrm{Sn}$ and $\mathrm{Ca}$ at higher temperatures compared with the melting point of $\mathrm{Pb}$, which resulted in the decrease of the micro shrinkage cavity. Hardness of Ca containing alloys was higher than that of Ca free alloys. The tensile properties were improved by addition of 0.25 mass\% $\mathrm{Ca}$, because of the decrease in micro shrinkage. [doi:10.2320/matertrans.48.799]
\end{abstract}

(Received August 25, 2006; Accepted January 12, 2007; Published March 25, 2007)

Keywords: bronzes, segregation, micro shrinkage cavity, solidification path, lead-free, calcium, environmentally friendly materials, substitute materials

\section{Introduction}

It is well known from the phase equilibrium of $\mathrm{Cu}-\mathrm{Sn}$ system that shrinkage cavities and blow holes are easily formed in bronze castings due to the wide melting range. ${ }^{1)} \mathrm{Zn}$ and $\mathrm{Pb}$ are added in the $\mathrm{Cu}-\mathrm{Sn}$ bronze because of improvement in castability and machinability, respectively, which results in promotion of formation of defects by solidification. ${ }^{2)}$ An appropriate counterplan has not been made against the formation of defects mentioned above. To investigate the segregation of alloying elements is important, because the formation of defects relates to characteristics in solidification.

Bronze and brass castings including a little amount of $\mathrm{Pb}$ have been used as main materials for pipe arrangements of water-supply. $\mathrm{Pb}$ in castings is easily eluted in water. The third edition of guidelines for drinking-water quality was published by World Health Organization, WHO, in 2004. ${ }^{3)}$ Effort for decrease or removal of $\mathrm{Pb}$ in these alloys has been carried out in Japan.

Bronze melts were often poured into a furan resin mold in the practical process. Sulfurous acid gas is formed in bronze during solidification at high temperature due to the presence of sulfur in the furan resin mold, which results in the formation of defects near a surface of castings. It is considered that formation of calcium sulfide or desulfurizing power by addition of $\mathrm{Ca}$ in alloys results in the decrease of solidification defects. In contrast, it is well known that freecutting and friction properties are improved by $\mathrm{Ca}$ addition in steels ${ }^{4)}$ and engine oils, ${ }^{5)}$ respectively. Therefore, the substitution of $\mathrm{Ca}$ for a part or all of $\mathrm{Pb}$ may be hopeful for improvement of their properties of $\mathrm{Cu}-\mathrm{Sn}-\mathrm{Zn}$ bronze alloys.

The substitution of $\mathrm{Ca}$ for a part or all of $\mathrm{Pb}$ in $\mathrm{Cu}-\mathrm{Sn}-\mathrm{Zn}$ alloys of 88-8-4 type was carried out in order to decrease solidification defects, and their melts were poured into both

*Graduate Student, Hiroshima University, Present address: Ehime Prefectural Police Station, Imabari 794-0026, Japan metal and furan resin molds which had a flight of four and five steps, respectively. The relation between cooling rate and segregation of alloying elements or solidification defects was investigated using the proposed alloys.

\section{Experimental Procedure}

\subsection{Preparation of bronze castings}

Chemical or nominal compositions of bronze ingots cast in this study are listed in Table 1.88 mass $\% \mathrm{Cu}-8$ mass $\% \mathrm{Sn}$ 4 mass $\%$ Zn, 88-8-4 alloy, defined as CAC402 in $\mathrm{JIS}^{6)}$ was selected as basic alloy. Limit of $\mathrm{Pb}$ as impurities is 1 mass $\%$ in CAC402. Ca of 0.02 to 1.0 mass\% was added in the 88 8-4 alloy. Molten alloys of $\mathrm{Cu}-\mathrm{Sn}-\mathrm{Zn}$ system were firstly prepared using mother alloy of $\mathrm{Cu}-12$ mass $\% \mathrm{Sn}$, pure $\mathrm{Cu}$ and pure $\mathrm{Zn}$, and were kept at $1533 \mathrm{~K}$ in air. $\mathrm{Ca}$ or $\mathrm{Pb}$ was added in these molten alloys. A Ca-44 mass\% Cu alloy was used for addition of $\mathrm{Ca}$, because its affinity for oxygen was higher. In order to achieve different cooling rate, four and five steps shaped molds which were made of the cast iron and furan resin sand, respectively, were used in solidification of alloys, and the shapes of cast ingots were shown in Figs. 1 and 2.

\subsection{Microstructural investigation}

Microstructural observations were carried out by an optical microscope and a scanning electron microscope, SEM, using polished surfaces of each step, A to E, in ingots shown in Figs. 1 and 2. Figure 3 shows schematic presentation for measurement paths of each element by electron probe micro analyzer (EPMA). Quantitative analyses for $\mathrm{Cu}, \mathrm{Sn}, \mathrm{Zn}, \mathrm{Pb}$ and $\mathrm{Ca}$ in more than 200 points on measurement paths (A-A in Fig. 3) between primary dendrite arms through interdendritic region ( $\mathrm{C}$ in Fig. 3) and grain boundary area (B in Fig. 3) including the solidification defects, were carried out by EPMA for preparation of the solidification path. The quantitative analyses were carried out in center area $(300 \times$ $300 \mu \mathrm{m}$ ) for part A with the thickness of $5 \mathrm{~mm}$ of the furan resin mold. Amounts of $\mathrm{Cu}, \mathrm{Sn}$ and $\mathrm{Zn}$ were plotted in 
Table 1 Compositions (mass\%) of some 88-8-4 system alloys used in this study.

\begin{tabular}{|c|c|c|c|c|c|c|c|}
\hline Alloys & $\mathrm{Cu}$ & $\mathrm{Sn}$ & $\mathrm{Zn}$ & $\mathrm{Pb}$ & $\mathrm{Ca}$ & $\mathrm{P}$ & Used mold \\
\hline $88-8-4$ & Bal. & 8.48 & 4.58 & - & - & - & Metal \\
\hline 88-8-4-1.0Pb (CAC402) & Bal. & 8.40 & 4.58 & 0.98 & - & - & Metal \\
\hline $88-8-4-0.25 \mathrm{Ca}$ & Bal. & 8.41 & 4.55 & - & 0.25 & - & Metal \\
\hline $88-8-4-0.5 \mathrm{Ca}$ & Bal. & 8.54 & 4.53 & - & 0.5 & - & Metal \\
\hline $88-8-4-1.0 \mathrm{Ca}$ & Bal. & 8.37 & 4.64 & - & 1.0 & - & Metal \\
\hline 88-8-4-0.5Pb-0.02P (CAC402) & Bal. & 8.1 & 4.6 & 0.5 & - & 0.0225 & Furan resin \\
\hline $88-8-4-0.5 \mathrm{~Pb}-0.02 \mathrm{Ca}$ & Bal. & 8.1 & 4.6 & 0.5 & 0.02 & - & Furan resin \\
\hline $88-8-4-0.5 \mathrm{~Pb}-0.05 \mathrm{Ca}$ & Bal. & 8.1 & 4.6 & 0.5 & 0.05 & - & Furan resin \\
\hline $88-8-4-0.5 \mathrm{~Pb}-0.1 \mathrm{Ca}$ & Bal. & 8.1 & 4.6 & 0.5 & 0.1 & - & Furan resin \\
\hline
\end{tabular}

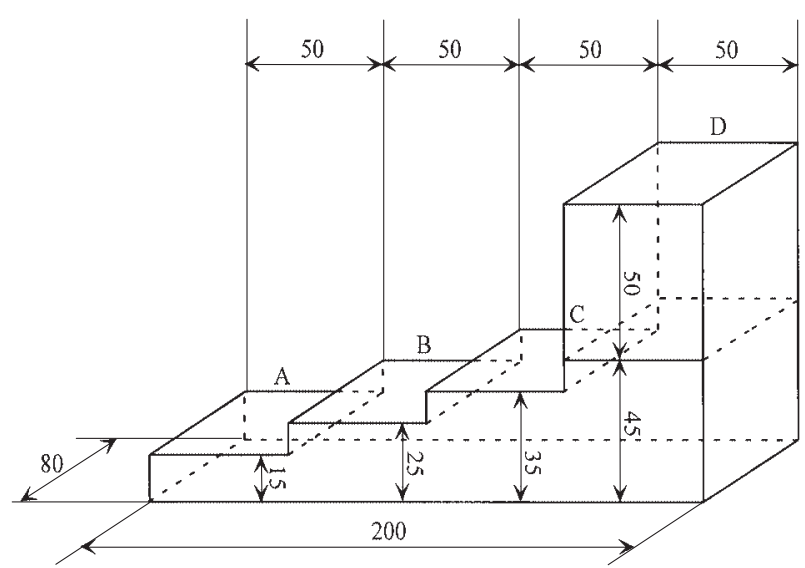

Fig. 1 Shape of the bronze castings poured into the metal mold.

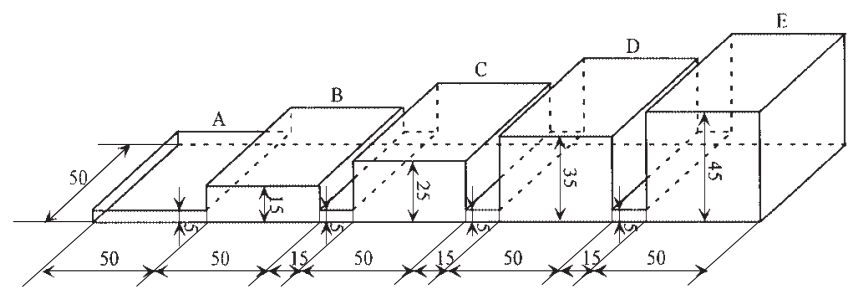

Fig. 2 Shape of the bronze castings poured into the furan resin mold.

triangularly compositional diagram, which was utilized as the solidification path showing the segregation course of alloying elements during solidification.

\subsection{Evaluation of mechanical properties}

Rockwell hardness number on B scale was measured on the center of each step, A-D, shown in Fig. 1. Button-head type tensile specimens with gauge diameters of $5 \mathrm{~mm}$ and gauge lengths of $16 \mathrm{~mm}$ were produced from the center in the step, B part, with the thickness of $25 \mathrm{~mm}$. Tensile tests were conducted at $293 \mathrm{~K}$ under an initial strain rate of $5 \times 10^{-4} \mathrm{~s}^{-1}$ in air.

\section{Results and Discussion}

\subsection{Microstructures}

The macro structure of each step of ingots was shown in Figs. 4 and 5 for $88-8-4-0.5 \mathrm{~Pb}-0.02 \mathrm{P}$ (CAC402) and 88-8-4$0.5 \mathrm{~Pb}-0.05 \mathrm{Ca}$ alloys cast into the furan resin mold, respectively. Equiaxed grains were predominantly observed in

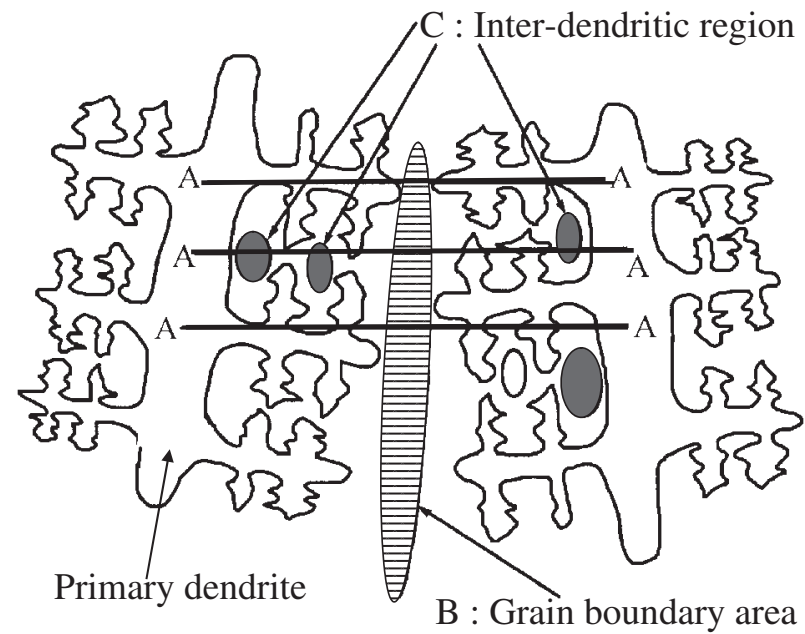

Fig. 3 Schematic presentation of measurement paths using the full lines, A to A, for quantitative analysis of some alloying elements by EPMA.

CAC402. In contrast, columnar grains were predominantly observed in the $\mathrm{Ca}$ added alloy, and a larger number of grains were shown, compared with CAC402.

Compositional images of part $\mathrm{A}$ and $\mathrm{D}$ with the thickness of 15 and $45 \mathrm{~mm}$ were shown in Fig. 6 for 88-8-4-0.5Ca and 88-8-4-1.0Pb, CAC402, castings poured into the metal mold. The finer dendrite structure was observed as cooling rate increased or the thickness of steps in the castings decreased, regardless of the kinds of alloys. In contrast, the finer dendrite structure was obtained by $\mathrm{Ca}$ addition in the 88-8-4 alloy. Behavior in inter-dendritic diffusion of Sn showing the inverse segregation was affected by kinds of ternary alloying elements in $\mathrm{Cu}-8$ mass\% $\%$ bronze alloys. ${ }^{7)}$ It is considered that finer dendrite structure in $\mathrm{Ca}$ added alloys was achieved due to decrease in both diffusion coefficient and mass transfer of $\mathrm{Sn}$ or $\mathrm{Zn}$ in the $\mathrm{Cu}$-liquid. For the part B with the thickness of $25 \mathrm{~mm}$ of both ingots, SEM views showing the microsegregation of alloying elements and concentration profiles of $\mathrm{Cu}, \mathrm{Sn}, \mathrm{Ca}$ or $\mathrm{Pb}$ are shown in Figs. 7 and 8. Segregation of $\mathrm{Sn}$ was shown in CAC402 such as the red or yellow marked area in its characteristic X-ray image in Fig. 7(b), and enrichment of $\mathrm{Pb}$ was also observed near Sn-enriched area. Copper depleted areas which was yellow or blue marked in its image, corresponded to the segregation of Sn. Micro shrinkage cavity was observed near Pb-enriched area, because of the wide melting range and lower melting point. In contrast, segregation of both $\mathrm{Sn}$ and $\mathrm{Ca}$ was observed in the 88-8-4-0.5Ca alloy as shown in Fig. 8, and both elements 


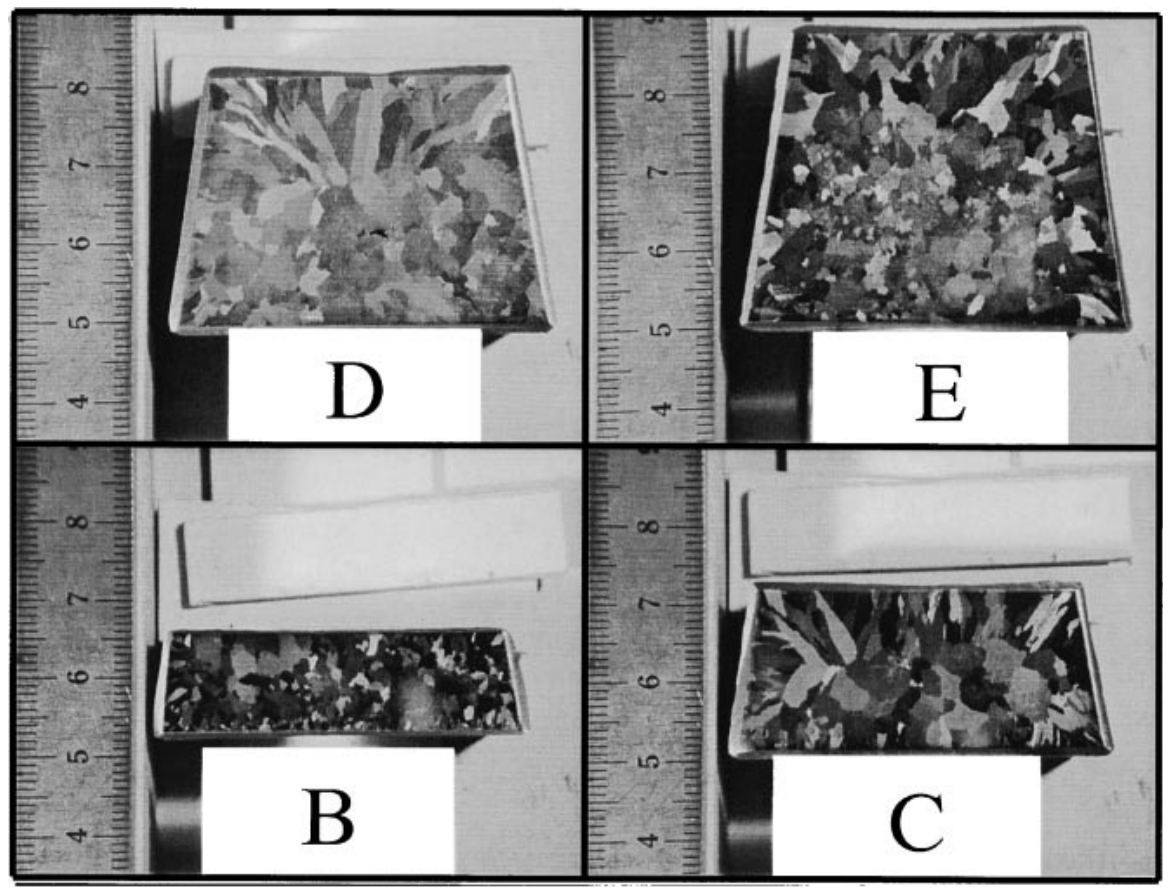

Fig. 4 Macrostructures in some steps, B, C, D, E with the thickness of 15, 25, 35 and $45 \mathrm{~mm}$, respectively, for the $88-8-4-0.5 \mathrm{~Pb}-0.02 \mathrm{P}$ (CAC402) casting poured into the furan resin mold.

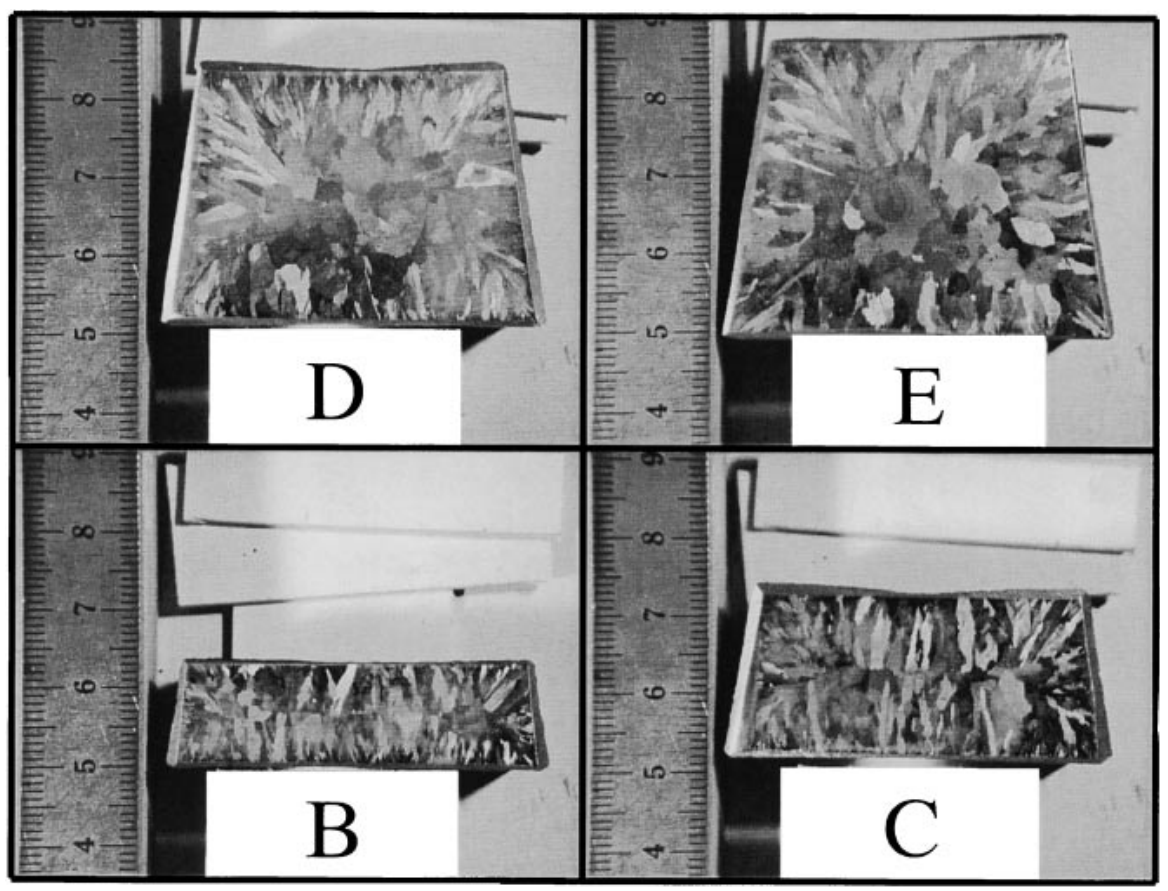

Fig. 5 Macrostructures in some steps, B, C, D, E with the thickness of 15, 25, 35 and $45 \mathrm{~mm}$, respectively, for the $88-8-4-0.5 \mathrm{~Pb}-0.05 \mathrm{Ca}$ casting poured into the furan resin mold.

segregated in the same area. The segregation area consisted of $\mathrm{Cu}, \mathrm{Sn}$ and $\mathrm{Ca}$. It is considered from Fig. 8 that some compounds of $\mathrm{Cu}-\mathrm{Sn}, \mathrm{Cu}-\mathrm{Ca}$ and $\mathrm{Ca}-\mathrm{Sn}$ systems such as $\mathrm{Cu}_{3} \mathrm{Sn}, \mathrm{Ca}_{4} \mathrm{Cu}, \mathrm{CaCu}_{5}, \mathrm{CaSn}_{3}$, etc, were formed in segregation area. The $\mathrm{Sn}$-segregated area in the $\mathrm{Ca}$ added alloy was smaller than that in CAC402. Micro shrinkage cavity was also observed near the segregation.

For the part A with the thickness of $5 \mathrm{~mm}$ of the 88-8-4$0.5 \mathrm{~Pb}-0.05 \mathrm{Ca}$ casting poured into the furan resin mold, concentration profiles of $\mathrm{Cu}, \mathrm{Sn}, \mathrm{Ca}$ and $\mathrm{Pb}$ are shown in Fig. 9. Segregation of $\mathrm{Sn}$ and $\mathrm{Ca}$ was observed in the same area and enrichment of $\mathrm{Pb}$ was also observed near $\mathrm{Sn}$ enriched area, which corresponded to the area showing the lower $\mathrm{Cu}$ level. Any solid solutions are not formed in the $\mathrm{Cu}$ $\mathrm{Pb}$ system and neither are any compound formed in the $\mathrm{Sn}-\mathrm{Pb}$ and $\mathrm{Zn}-\mathrm{Pb}$ systems. It is considered that $\mathrm{Pb}$ was discharged into the residual liquid and crystallized near the Sn-enriched area which was formed in the final stage of solidification. In 


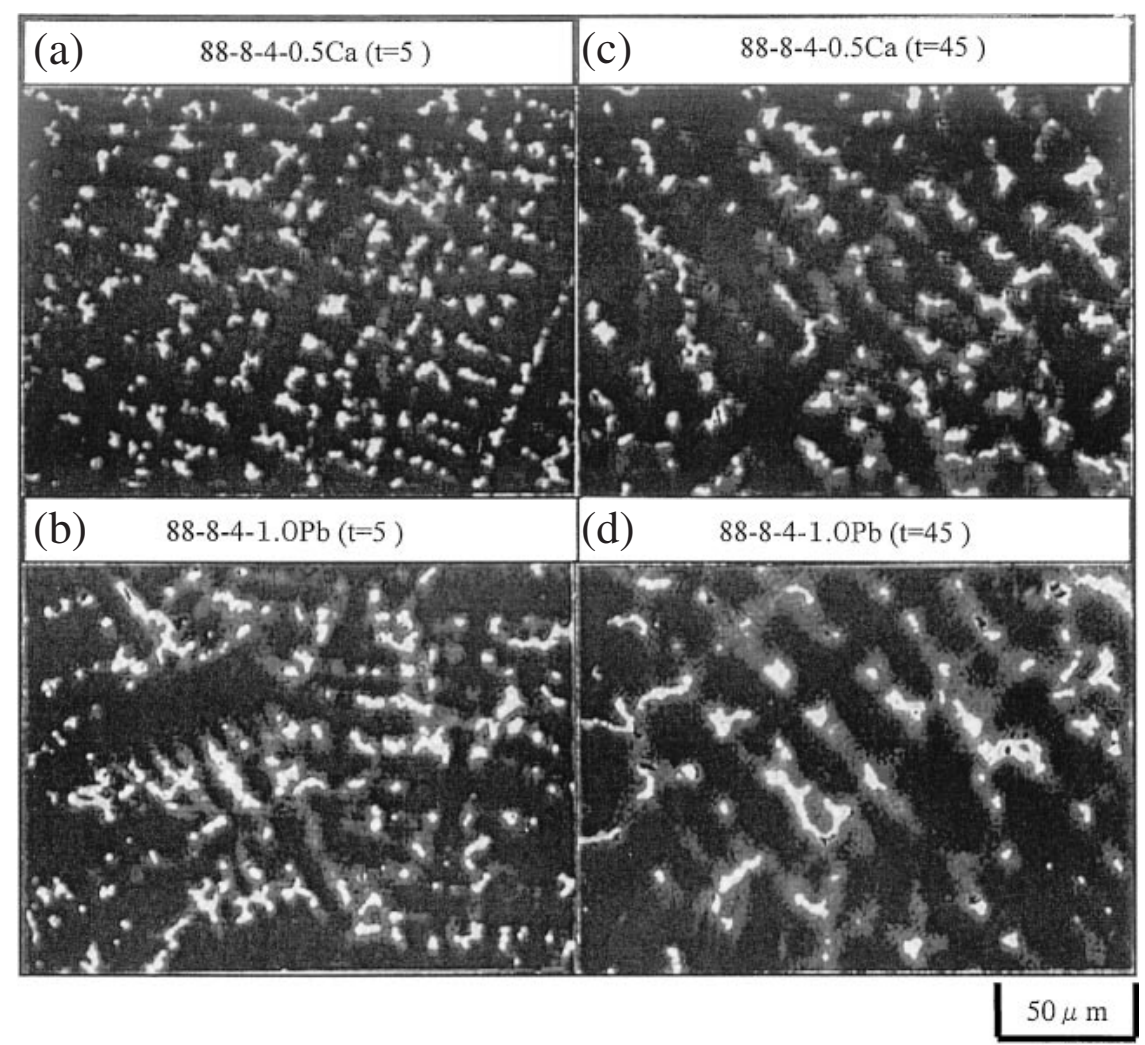

Fig. 6 Compositional images of the steps with the thickness of (a), (b) 5 and (c), (d) $45 \mathrm{~mm}$ in (a), (c) 88-8-4-0.5Ca and (b), (d) 88-8-4$1.0 \mathrm{~Pb}(\mathrm{CAC} 402)$ castings poured into the metal mold.

contrast, any solid solutions are not formed in the $\mathrm{Cu}-\mathrm{Ca}, \mathrm{Sn}$ $\mathrm{Ca}$ and $\mathrm{Zn}-\mathrm{Ca}$ systems. It is considered that $\mathrm{Ca}$ was also discharged into the residual liquid and segregated with $\mathrm{Sn}$ as the compounds in the final stage of solidification.

It is considered that formation of micro shrinkage cavity was promoted due to concentration of solute elements in the residual liquid in the latest stage of solidification, solidification-shrinkage, long solidification-temperature range, slower cooling rate, etc, as seen in Fig. 7. The relation among cooling rate, macro-composition, and area fraction of micro shrinkage cavity was investigated for $88-8-4-1.0 \mathrm{~Pb}$ (CAC402) and 88-8-4-0.5Ca alloys cast into the metal mold. Chemical analyses for $\mathrm{Cu}, \mathrm{Sn}, \mathrm{Zn}, \mathrm{Pb}$ and $\mathrm{Ca}$ were carried out by the wet method using parts which were located at center $(10 \times 10 \mathrm{~mm})$ of each step $(\mathrm{A}-\mathrm{D})$ in castings. It is considered that chemical composition of each element was exactly measured by methods mentioned above. For CAC402, the concentration of $\mathrm{Pb}$ and $\mathrm{Sn}$ increased and decreased, respectively, as the thickness of each step in the casting increased or the cooling rate decreased, as shown in Fig. 10. $\mathrm{Sn}$ and $\mathrm{Pb}$ showed the inverse and normal segregation, because segregation of $\mathrm{Sn}$ and $\mathrm{Pb}$ were mainly caused at higher and lower temperatures, respectively. Even at lower temperature the liquid was supplied in the un-solidified part on each step, from a hot top in part " $D$ " showing macro shrinkage porosity, see Fig. 10(a). The concentration of $\mathrm{Zn}$ was almost constant because $\mathrm{Cu}$ and $\mathrm{Zn}$ formed a complete solid solution in the compositional range of less than 39 mass $\% \mathrm{Zn}$, regardless of the difference in the cooling rate. The area fraction of the micro shrinkage cavity increased as the amount of macro segregation of $\mathrm{Pb}$ was increased according with the decrease of the cooling rate. It is found that the micro shrinkage cavity was caused by the macro segregation of $\mathrm{Pb}$ in CAC402. In contrast, for 88-8-4-0.5Ca alloy, the concentration of $\mathrm{Ca}$ and $\mathrm{Zn}$ was almost constant, regardless of the difference in the cooling rate, as shown in Fig. 11. Also, inverse segregation of Sn was observed in this figure and its concentration was changed depending on the position of the metal mold. The segregation behavior of each element was affected by its segregation temperature and supply of liquid from a hot top as mentioned above. The concentration of Sn decreased as the cooling rate decreased. The macro segregation of $\mathrm{Ca}$ was not found in this alloy, although that of $\mathrm{Pb}$ was caused in CAC402, as shown in Fig. 10. The area fraction of micro shrinkage cavity was almost constant, regardless of the difference in the cooling rate. The amount of micro shrinkage cavity in the $\mathrm{Ca}$ added alloy was smaller than that in CAC402. Feeding capability of the 88-8-4-0.5Ca melt was improved, because the melt flowed easily in columnar structures which were formed by $\mathrm{Ca}$ addition, see Fig. 5. Figure 12 shows micro shrinkage cavity in part $\mathrm{D}(\mathrm{t}=45)$ showing lowest cooling rate of both CAC402 and 88-8-4-0.5Ca castings. The Ca containing alloy showed smaller micro shrinkage cavity, although there was almost same number of shrinkage cavity in both castings.

It is found from the result mentioned above that the $\mathrm{Ca}$ added alloy showed the finer microstructure. Figure 13 shows the secondary dendrite arm spacings measured on some 88-8-4 system bronze castings poured into metal and furan resin molds. The secondary dendrite arm spacings increased as the cooling rate decreased, regardless of the kinds of castings and molds. For the castings poured into the 


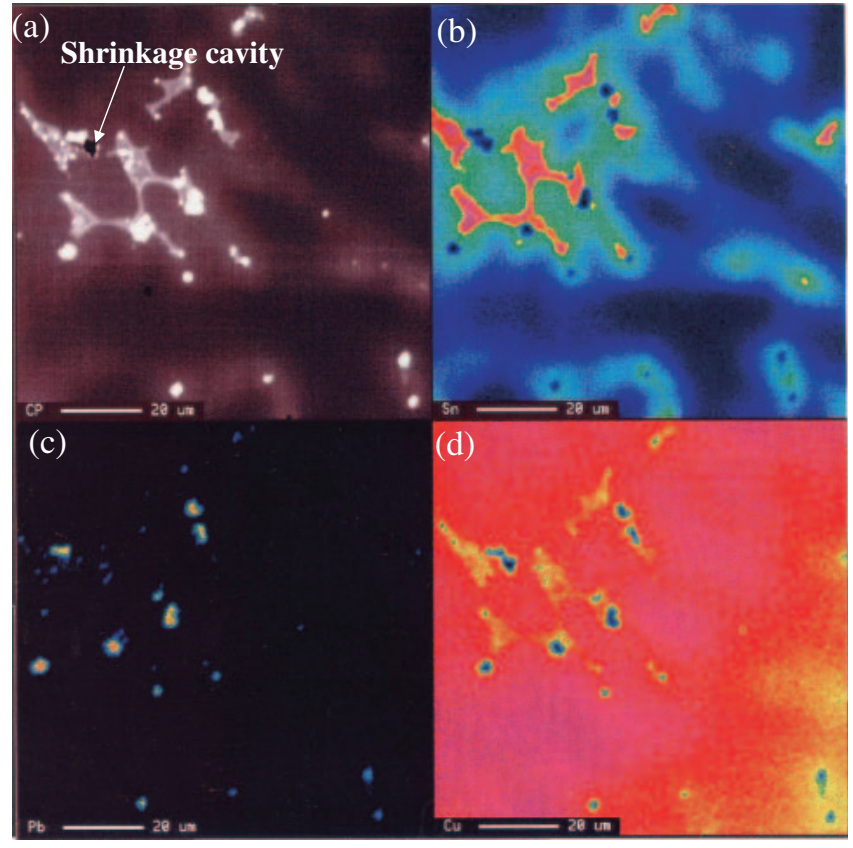

Fig. 7 (a) A scanning electron microscopic image, (b), (c), (d) concentration profiles of $\mathrm{Sn}, \mathrm{Pb}$ and $\mathrm{Cu}$, respectively, in the vicinity of the solidification defect in the step with the thickness of $25 \mathrm{~mm}$, for the 88-8$4-1.0 \mathrm{~Pb}(\mathrm{CAC} 402)$ casting poured into the metal mold.

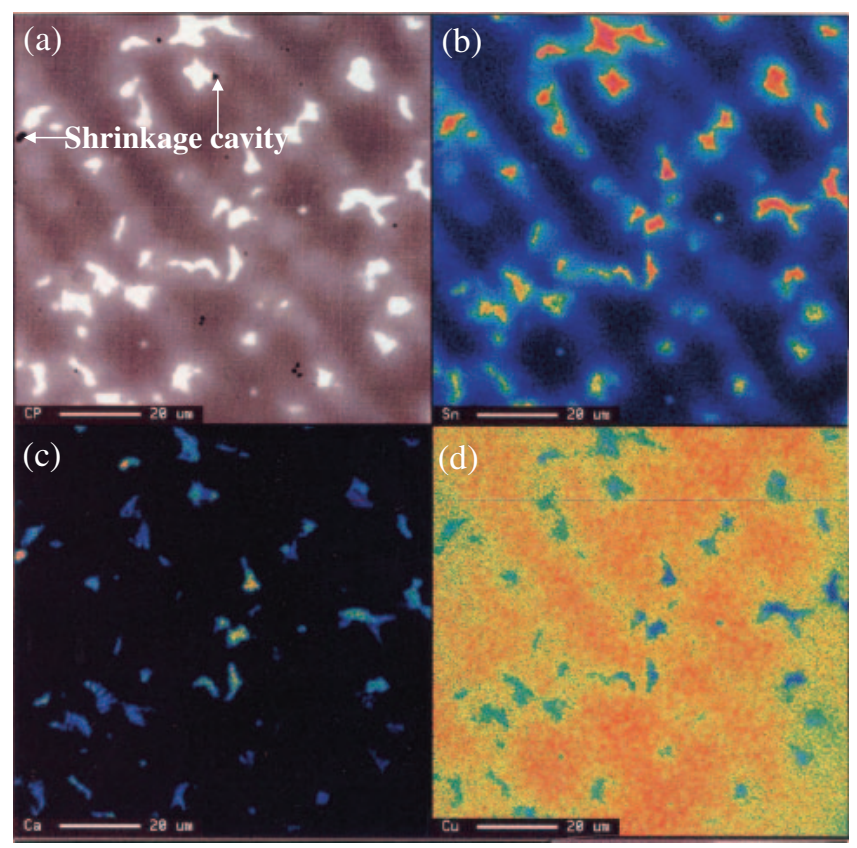

Fig. 8 (a) A scanning electron microscopic image, (b), (c), (d) concentration profiles of $\mathrm{Sn}, \mathrm{Ca}$ and $\mathrm{Cu}$, respectively, in the vicinity of the solidification defect in the step with the thickness of $25 \mathrm{~mm}$, for the 88-84-0.5Ca casting poured into the metal mold.

metal mold, the shorter secondary dendrite arm spacings was shown, compared with those poured into the furan resin mold. Secondary dendrite arm spacings of the $\mathrm{Ca}$ added castings were shorter than that of the Ca free 88-8-4 castings. In contrast, the castings poured into the furan resin mold showed the similar tendency as those poured into the metal mold, for the relation among the secondary dendrite arm spacings, $\mathrm{Ca}$ addition and cooling rate.

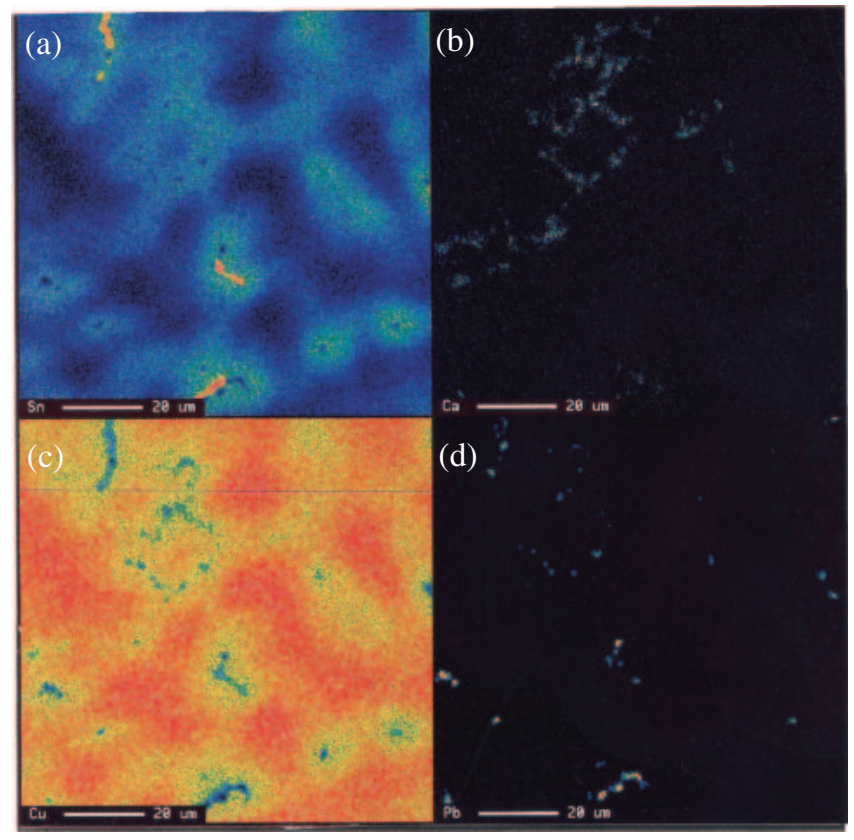

Fig. 9 (a), (b), (c), (d) Concentration profiles of $\mathrm{Sn}, \mathrm{Ca}, \mathrm{Cu}$ and $\mathrm{Pb}$, respectively, in the step with the thickness of $5 \mathrm{~mm}$, for the $88-8-4-0.5 \mathrm{~Pb}$ $0.05 \mathrm{Ca}$ casting poured into the furan resin mold.

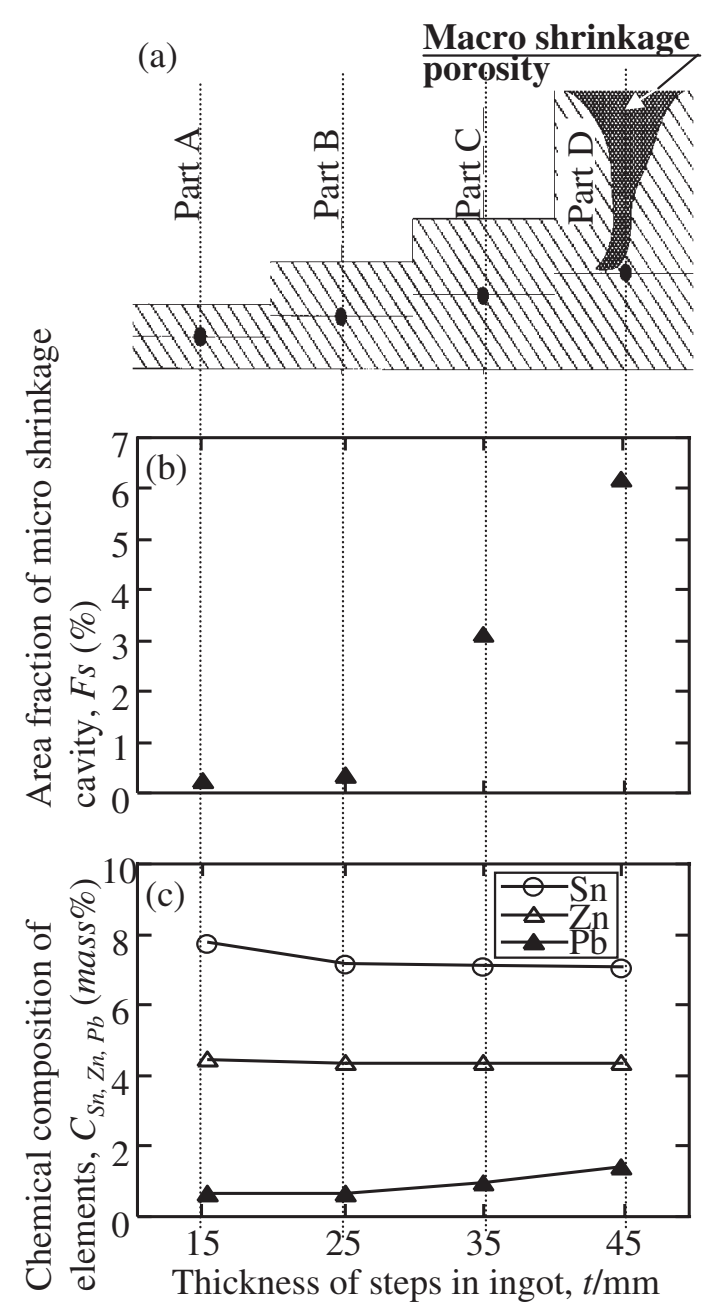

Fig. 10 Relation among (a) cross sections of steps with $15-45 \mathrm{~mm}$ thickness, (b) area fraction of micro shrinkage cavity and (c) chemical composition of alloying elements in each step, for the $88-8-4-1.0 \mathrm{~Pb}$ (CAC402) casting poured into the metal mold. 


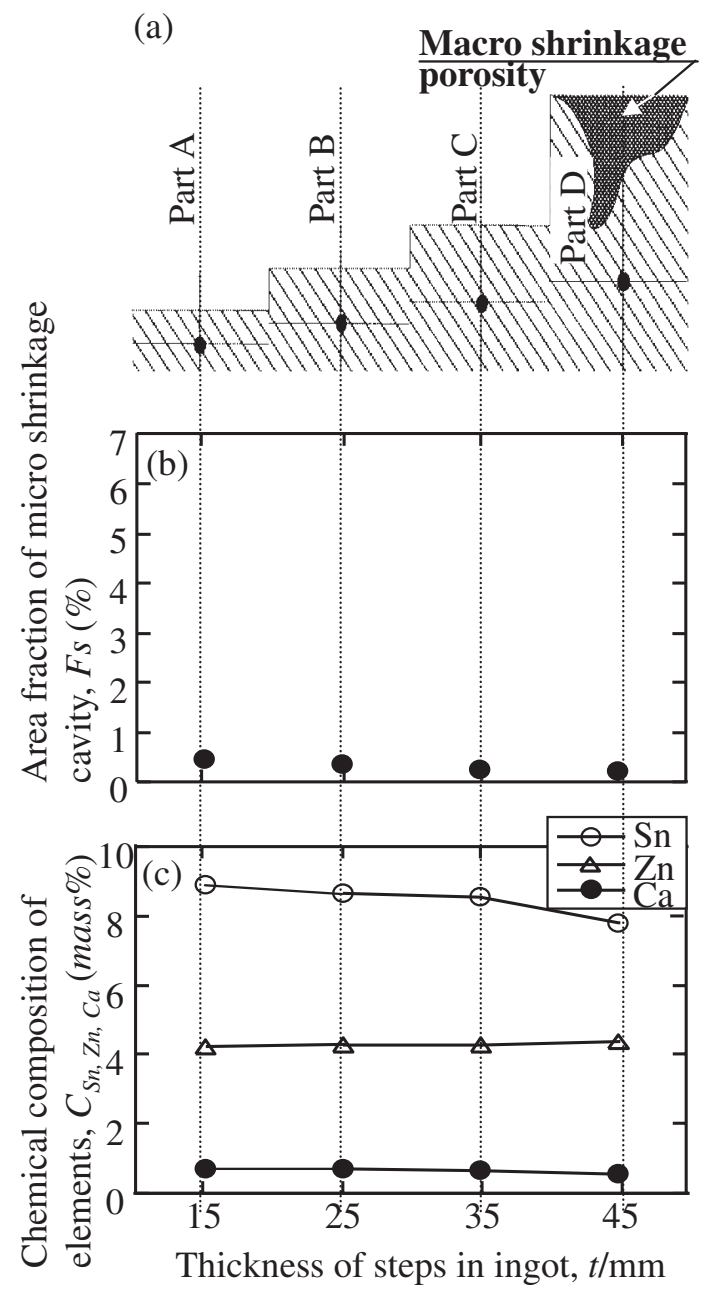

Fig. 11 Relation among (a) cross sections of steps with $15-45 \mathrm{~mm}$ thickness, (b) area fraction of micro shrinkage cavity and (c) chemical composition of alloying elements in each step, for the 88-8-4-0.5Ca casting poured into the metal mold.

\subsection{Solidification path}

The solidification path was prepared to investigate a segregation course of alloying elements in the step with the thickness of $5 \mathrm{~mm}$ for 88-8-4-0.5Pb-0.02P (CAC402) and 88$8-4-0.5 \mathrm{~Pb}-0.05 \mathrm{Ca}$ castings poured into the furan resin mold. It of both ingots was shown in Figs. 14 and 15, respectively, using triangularly compositional representation of $\mathrm{Cu}, \mathrm{Sn}$ and $\mathrm{Zn}$. The average chemical compositions were shown using an open circle symbol in the figures. The same segregation course in the solidification path was shown in both alloys. The concentration of 40 mass $\%$ Sn was observed in final stage of solidification for $\mathrm{Pb}$ added CAC402, as shown in Fig. 13. The higher concentration of $40-70$ mass $\%$ in $\mathrm{Pb}$ was shown near the average composition of the alloy, because of two melts consisting of $\mathrm{Cu}-36$ mass $\% \mathrm{~Pb}$ and $\mathrm{Cu}-87$ mass\% $\mathrm{Pb}$. $\mathrm{Pb}$-concentrated liquid was formed from the $\mathrm{Cu}-87$ mass $\% \mathrm{~Pb}$ melt in the inter-dendritic region. In contrast, the concentration of 30 mass $\%$ Sn was observed in final stage of solidification as shown in Fig. 15, and the compounds $\left(\mathrm{Ca}_{2} \mathrm{Sn}, \mathrm{CaSn}\right.$ and $\left.\mathrm{CaSn}_{3}\right)$ consisting of $\mathrm{Ca}$ and $\mathrm{Sn}$ were formed depending on their melting points, in the $\mathrm{Pb}$ and $\mathrm{Ca}$ containing alloy.

In the Pb-containing and Ca-free alloy (CAC402), the
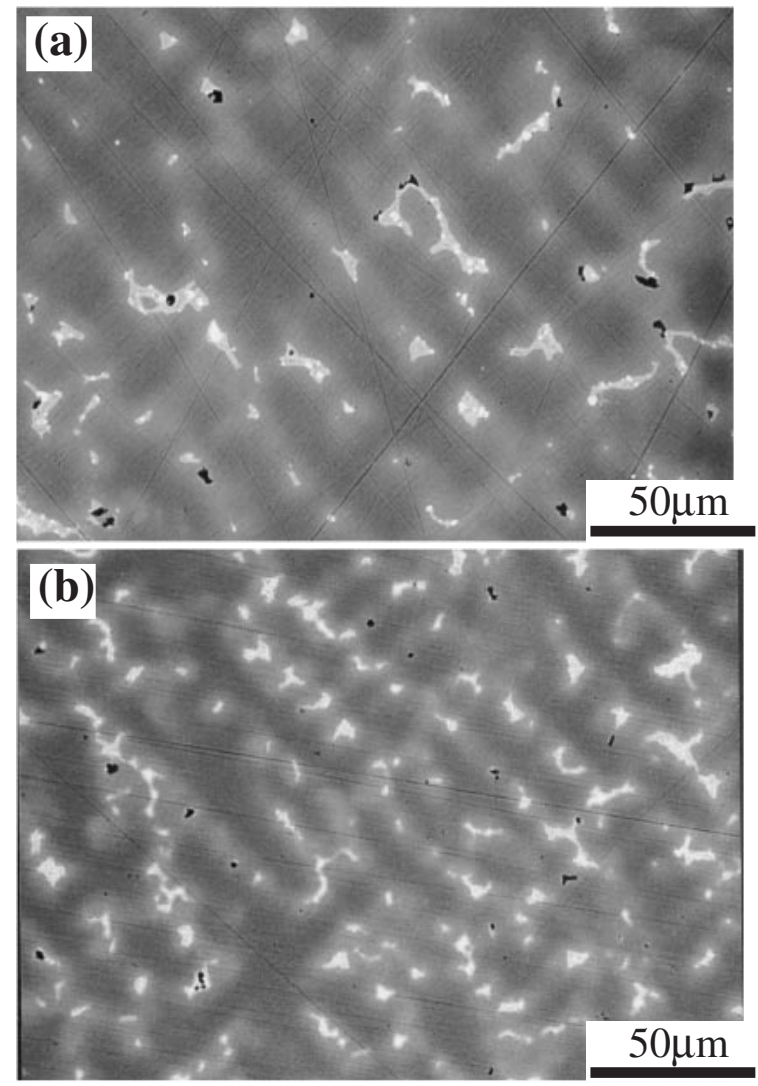

Fig. 12 Compositional images of the step with the thickness of $45 \mathrm{~mm}$ in (a) $88-8-4-1.0 \mathrm{~Pb}(\mathrm{CAC} 402)$ and (b) $88-8-4-0.5 \mathrm{Ca}$ castings poured into the metal mold.

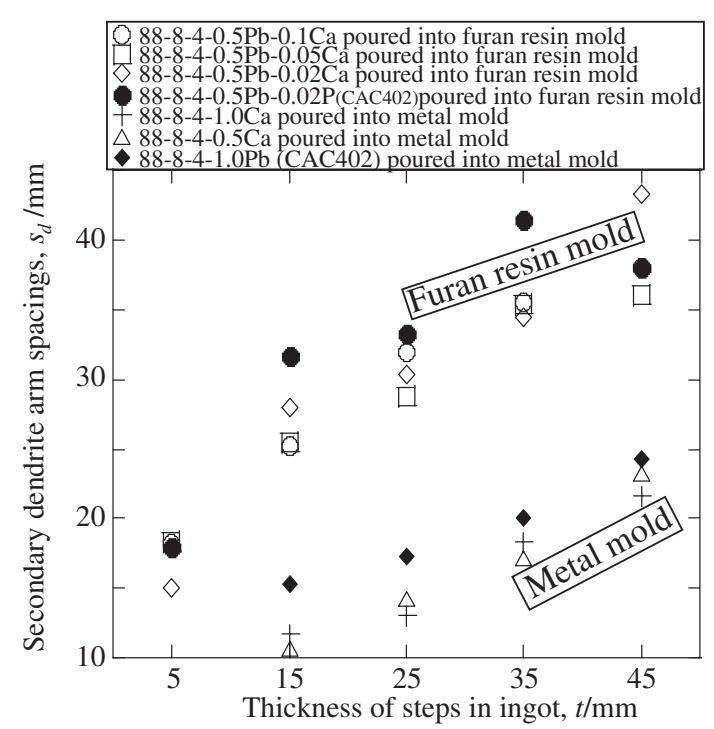

Fig. 13 Secondary dendrite arm spacings obtained from some 88-8-4 system bronze castings poured into the metal and furan resin molds.

solidification was completed at melting point $(600 \mathrm{~K})$ of $\mathrm{Pb}$, by crystallization of $\mathrm{Pb}$ from the residual liquid showing the higher $\mathrm{Sn}$ concentration, compared with that in the $\mathrm{Ca}$ added alloy, as shown in Figs. 14 and 15. It is considered that the solidification defect was caused by the enrichment of $\mathrm{Pb}$ in the residual liquid and the shrinkage due to the solidification, and when its enrichment in the residual liquid was remarkable, the micro shrinkage cavity became large. In contrast, by 


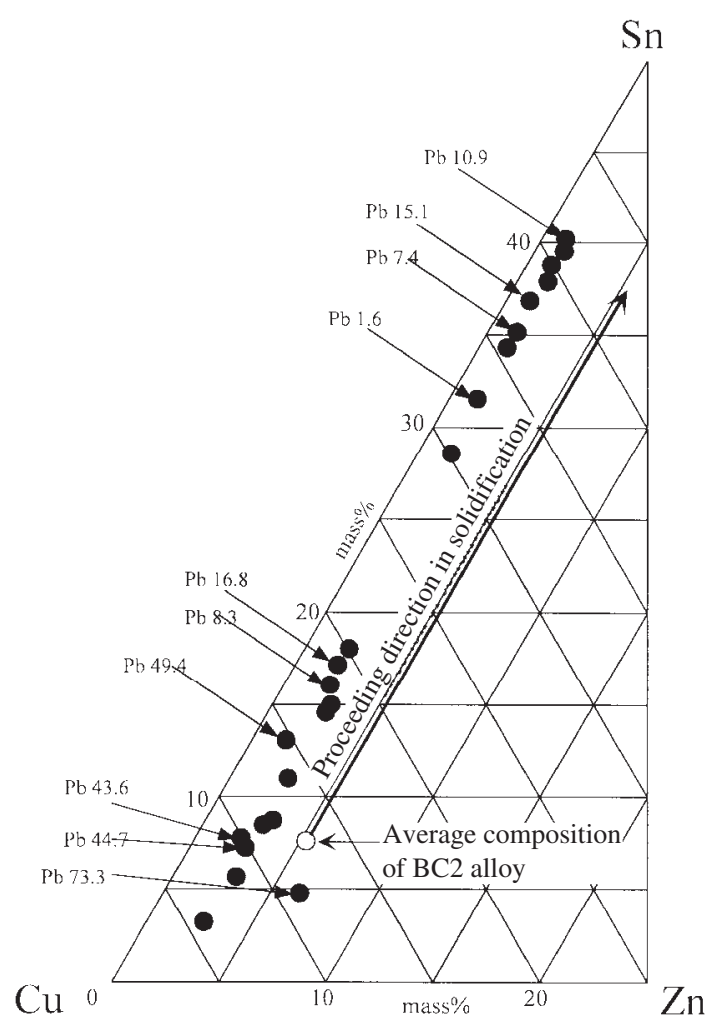

Fig. 14 Solidification path obtained from the step with the thickness of $5 \mathrm{~mm}$ in the $88-8-4-0.5 \mathrm{~Pb}-0.02 \mathrm{P}$ (CAC402) casting poured into the furan resin mold.

$\mathrm{Ca}$ addition, the enrichment of $\mathrm{Sn}$ in the residual liquid and decrease in temperature of last stage in solidification were suppressed by expenditure of $\mathrm{Sn}$ due to formation of the compounds consisting of $\mathrm{Sn}$ and $\mathrm{Ca}$ at higher temperatures compared with the melting point of $\mathrm{Pb}$, which resulted in the decrease of the micro shrinkage cavity. Ca enriched area did not exactly corresponded to all micro shrinkage cavities, see Figs. 8, 12, which meant the complete completion of solidification by formation of $\mathrm{Cu}-\mathrm{Sn}$ compounds such as $\mathrm{Cu}_{3} \mathrm{Sn}$, in castings at lower temperature, compared with one for formation of compounds consisting of $\mathrm{Ca}$ and $\mathrm{Sn}$ or $\mathrm{Cu}$. The amount of micro shrinkage cavity was decreased, because the amount of $\mathrm{Cu}-\mathrm{Sn}$ compounds became lower due to the expenditure of $\mathrm{Sn}$ in $\mathrm{Ca}$ added castings as shown in Fig. 15.

Inverse segregation of Sn was reported in this alloying system and affected by some factors such as dendrite morphology, solidification-temperature range, evolution of gas bubbles, distribution and diffusion coefficient of the solute, etc. ${ }^{7-12)}$ Inverse segregation of Sn was shown in both $\mathrm{Ca}$-free and -added castings as shown in Fig. 10 and 11. The degree of the segregation is affected by the dendrite arm spacings of the primary $\alpha$ phase ${ }^{13)}$ which is one of factors for the inverse segregation. The dendrite arm spacings are strongly affected by local cooling time in solidification. The same local cooling time was shown among experimental alloys, regardless of Ca-free and -addition alloys. It is considered that the difference in solidification behavior between $\mathrm{Ca}$-free and -addition alloys, was caused by decrease of dendrite arm spacings due to decrease in the diffusion coefficient and mass transfer of $\mathrm{Sn}$ and/or $\mathrm{Zn}$ in the liquid for

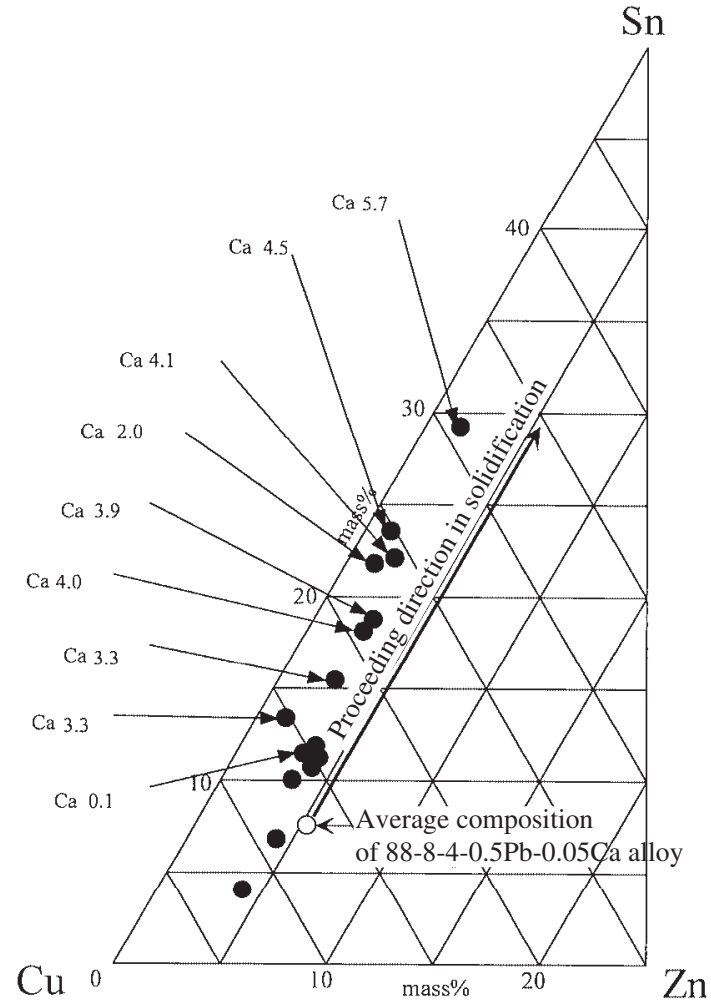

Fig. 15 Solidification path obtained from the step with the thickness of $5 \mathrm{~mm}$ in the $88-8-4-0.5 \mathrm{~Pb}-0.05 \mathrm{Ca}$ casting poured into the furan resin mold.

$\mathrm{Ca}$ addition alloys. The size of segregation decreased by expenditure of $\mathrm{Sn}$ and suppression of its diffusion due to formation the compounds consisting of $\mathrm{Sn}$ and $\mathrm{Ca}$, which corresponded to the shorter secondary dendrite arm spacings in the Ca-addition alloys, as shown in Fig. 13.

$\mathrm{Ca}$-addition in castings poured into the furan resin mold is hopeful in the view point of the decrease of solidification defects due to three reasons as follows. (1) The lower level in Sn-concentration was observed in latest stage of solidification in the Ca containing castings, compared with the higher one of Ca-free castings, as shown in Figs. 14, 15. (2) Shorter secondary dendrite arm spacings were obtained in $\mathrm{Ca}$ containing castings. (3) The formation of defects which were caused by sulfur in the furan resin mold, was suppressed because of desulfurizing power of $\mathrm{Ca}$.

\subsection{Mechanical properties}

For four alloys, 88-8-4-1.0Pb (CAC402), 88-8-4-1.0Ca, $88-8-4-0.5 \mathrm{Ca}$ and $88-8-4$, poured into the metal mold, Rockwell hardness number on B scale $\left(\mathrm{H}_{\mathrm{R}} \mathrm{B}\right)$ was measured and the result was shown in Fig. 16. Hardness decreased as the microstructure coarsened or thickness of steps in the metal mold increased, regardless of the kinds of alloys. The hardness of cast metals correlates with their solidified structure, ${ }^{14)}$ which agrees with this result. Hardness of Cacontaining alloys was higher than that of Ca-free alloys. Also, the relation between $\mathrm{Ca}$ contents in the 88-8-4 system alloys and $\left(\mathrm{H}_{\mathrm{R}} \mathrm{B}\right)$ is shown in Fig. 17. Hardness increased as the $\mathrm{Ca}$ content increased in alloys, because of the increase of the compounds consisting of $\mathrm{Sn}$ and $\mathrm{Ca}$ crystallized in interdendritic region.

For three alloys, 88-8-4-1.0Pb (CAC402), 88-8-4-0.25Ca 


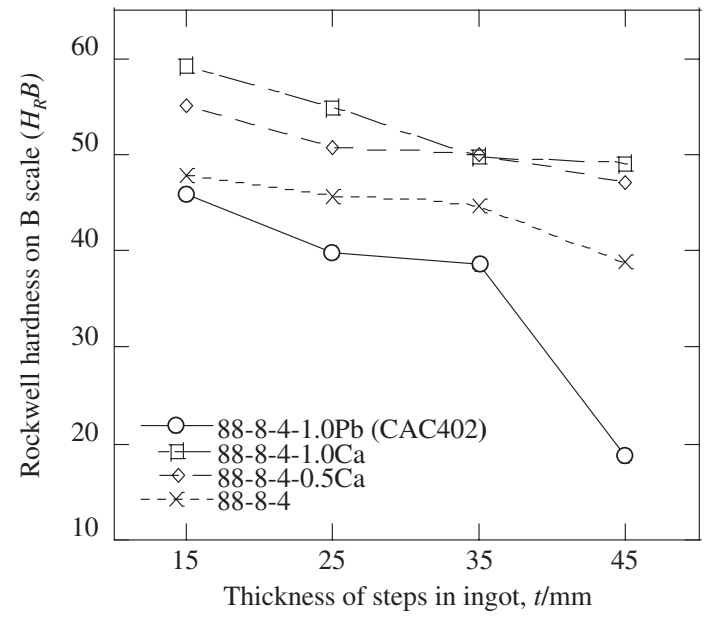

Fig. 16 Relation between Rockwell hardness number on B scale and the thickness of steps in castings, for some 88-8-4 system bronze castings poured into the metal mold.

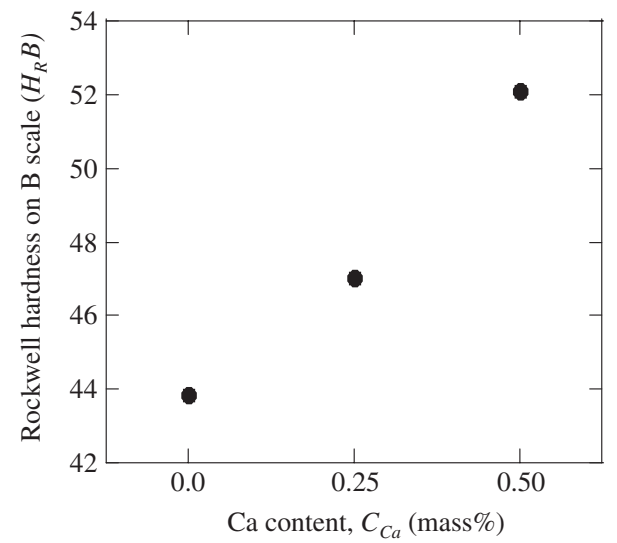

Fig. 17 Effect of $\mathrm{Ca}$ content in the 88-8-4 system bronze castings on Rockwell hardness number on B scale.

and $88-8-4-0.5 \mathrm{Ca}$, poured into the metal mold, the $0.2 \%$ proof strength, ultimate tensile strength and fracture elongation obtained from tensile test at $293 \mathrm{~K}$ were shown in Fig. 18. The $0.2 \%$ proof strength, ultimate tensile strength and fracture elongation were increased by the addition of 0.25 mass\% Ca, compared with CAC402, because of decrease in the amount of micro shrinkage cavity in Ca-added alloy. In contrast, for the 0.5 masss $\% \mathrm{Ca}$ added alloy, the lower elongation and same strength were shown, compared with the $0.25 \mathrm{Ca}$ added alloy.

\section{Conclusions}

(1) Finer dendrite structure was obtained due to decrease in the diffusion coefficient and mass transfer of Sn and/or $\mathrm{Zn}$ in the $\mathrm{Cu}$-liquid in Ca-addition alloy.

(2) The concentration of $\mathrm{Pb}$ and the amount of the micro shrinkage cavity increased as the cooling rate decreased in CAC402. In contrast, the concentration of $\mathrm{Ca}$ and the amount of the micro shrinkage cavity was almost constant in $\mathrm{Ca}$ added alloys, regardless of the difference in the cooling rate.

(3) The same segregation course in the solidification path

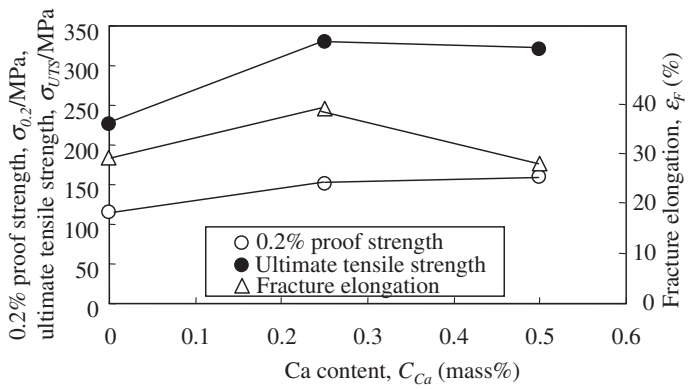

Fig. 18 Effect of Ca content in the 88-8-4 system bronze castings, 88-8-4$1.0 \mathrm{~Pb}$ (CAC402), $88-8-4-0.25 \mathrm{Ca}, 88-8-4-0.5 \mathrm{Ca}$, on the $0.2 \%$ proof strength, ultimate tensile strength and fracture elongation.

showed in both CAC402 and Ca added alloys.

(4) For CAC402, Sn was segregated in the area solidified in last stage and enrichment of $\mathrm{Pb}$ was also observed near Sn-segregated area. Micro shrinkage cavity was affected by crystallization of $\mathrm{Pb}$ at its melting point, the solidification-shrinkage, long solidification temperature range, behavior of solute elements and cooling rate. In contrast, by $\mathrm{Ca}$ addition, the enrichment of $\mathrm{Sn}$ in the residual liquid and decrease in latest solidified temperature were suppressed by expenditure of $\mathrm{Sn}$ due to formation of the compounds consisting of $\mathrm{Sn}$ and $\mathrm{Ca}$ at higher temperatures compared with the melting point of $\mathrm{Pb}$, which resulted in the decrease of the micro shrinkage cavity.

(5) Hardness of $\mathrm{Ca}$ containing alloys was higher than that of $\mathrm{Ca}$ free alloys. Hardness increased as the $\mathrm{Ca}$ content increased in alloys, because of the increase of the compounds consisting of $\mathrm{Sn}$ and $\mathrm{Ca}$ crystallized in inter-dendrite grains. In contrast, the $0.2 \%$ proof strength, ultimate tensile strength and fracture elongation were increased by addition of $0.25 \% \mathrm{Ca}$, because of the decrease in the amount of micro shrinkage cavity in the Ca-containing alloy.

\section{REFERENCES}

1) M. Sugiyama: Nonferrous Materials, (Corona Publishing Co., Ltd., Tokyo, 1982) pp. 48-68.

2) K. Ohishi, T. Matsumoto and T. Ohkubo: Materia Japan 39 (2000) 9092.

3) World Health Organization: Third Edition of Guidelines for DrinkingWater Quality, (WHO, 2004).

4) M. Kikuchi, M. Maki, K. Sakuma, H. Sudo, I. Tamura and R. Tanaka: Ferrous Materials, (The Japan Institute of Metals, Sendai, 1985) p. 110-111.

5) Y. Ma, W. Zhao, S. Li, Y. Jin, Y. Wang and T. C. Simon: Industriacl Lubrication and Tribology 57 (2005) 161-167.

6) Japanese Industrial Standard, Standard of Bronze Ingots (JIS H 5120), Japanese Standards Association (2006) p. 1044-1051.

7) K. Nakano and S. Oya: Imono 47 (1975) 73-78.

8) K. Nakano, K. Suzuki, T. Takada and S. Oya: Imono 45 (1973) 878886.

9) K. Nakano, K. Suzuki and S. Oya: Imono 45 (1973) 954-961.

10) K. Nakano and S. Oya: Imono 46 (1974) 988-992.

11) K. Nakano, M. Aoki and S. Oya: Imono 46 (1974) 1031-1035.

12) K. Nakano and S. Oya: Imono 47 (1975) 15-20.

13) B. Chalmers (Translation by T. Okamoto, A. Suzuki): Principle of Solidification, (Maruzen Publishing Co., Ltd., Tokyo, 1971) p. 159.

14) T. Umeda, H. Takeuchi and M. Sugiyama: Imono 49 (1977) 345-349. 